\title{
A Transcription-Dependent Switch Controls Competence of Adult Neurons for Distinct Modes of Axon Growth
}

\author{
Deanna S. Smith ${ }^{1,2}$ and J. H. Pate Skene ${ }^{1}$ \\ Departments of ${ }^{1}$ Neurobiology and ${ }^{2}$ Genetics, Duke University Medical Center, Durham, North Carolina 27710
}

\begin{abstract}
Although maturing neurons undergo a precipitous decline in the expression of genes associated with developmental axon growth, structural changes in axon arbors occur in the adult nervous system under both normal and pathological conditions. Furthermore, some neurons support extensive regrowth of long axons after nerve injury. Analysis of adult dorsal root ganglion (DRG) neurons in culture now shows that competence for distinct types of axon growth depends on different patterns of gene expression. In the absence of ongoing transcription, newly isolated neurons can extend compact, highly branched arbors during the first day in culture. Neurons subjected to peripheral axon injury 2-7 d before plating support a distinct mode of growth characterized by rapid extension of long, sparsely branched axons. A transition from "arborizing" to "elongating" growth occurs in naive adult neurons after $\sim 24 \mathrm{hr}$ in culture but requires a discrete period of new transcription after removal of the ganglia from the intact animal. Thus, peripheral axotomy - by nerve crush or during removal of DRGs-
\end{abstract}

Both the nature and the extent of axon growth in the adult nervous system have been subjects of conflicting hypotheses for many years. After contacting their targets, the motile growth cones of developing axons transform over time into mature synaptic terminals with new functions and a distinct complement of proteins (Hall and Sanes, 1993). For most neurons, this transformation includes a decrease in expression of several prominent growth cone components (Skene and Willard, 1986; Basi et al., 1987; Miller et al., 1987; Maness et al., 1988; Chu et al., 1989; Hoffman, 1989; Strittmatter et al., 1990; Caroni and Becker, 1992). These findings support an earlier suggestion that competence for axon growth is lost or restricted in most neurons after they reach maturity (Skene and Willard, 1981a,b). Such a model is consistent with long-standing evidence that neurons in many parts of the nervous system display an abrupt decline in their capacity for growth and remodeling of synaptic connections after a critical period of development (Purves, 1988; Antonini and Stryker, 1993; O'Leary et al., 1994).

Paradoxically, some forms of axon growth appear to be common in adult nervous systems. Subtle reorganization of terminal arbors is thought to occur throughout life and may underlie some aspects of learning and memory (Purves et al., 1987; Greenough and Bailey, 1988; Walters et al., 1991; Wooley and McEwen, 1992;

Received Aug. 6, 1996; revised Sept. 23, 1996; accepted Oct. 22, 1996.

This work was supported by National Institutes of Health Grant NS20178/EY11475.

Correspondence should be addressed to Pate Skene, Department of Neurobiology, Box 3209, Duke University Medical Center, Durham, NC 27710.

Copyright (C) 1997 Society for Neuroscience $\quad 0270-6474 / 97 / 170646-13 \$ 05.00 / 0$ induces a transcription-dependent change that alters the type of axon growth that can be executed by these adult neurons. This transition appears to be triggered, in large part, by interruption of retrogradely transported signals, because blocking axonal transport in vivo can elicit competence for elongating growth in many DRG neurons. In contrast to peripheral axotomy, interruption of the centrally projecting axons of DRG neurons in vivo leads to subsequent growth in vitro that is intermediate between "arborizing" and "elongating" growth. This suggests that the transition between these two modes of growth is a multistep process and that individual steps may be regulated separately. These observations together suggest that structural remodeling in the adult nervous system need not involve the same molecular apparatus as long axon growth during development and regeneration.

Key words: axon regeneration; sprouting; adult plasticity; growth cone; GAPs; axotomy

Delree et al., 1993). More exuberant sprouting can be evoked by changes in neural activity, by neurotrophic factors, and by a variety of other physiological and pathological conditions (Touck and Nadler, 1985; Diamond et al., 1987; Cavazos et al., 1991; Bailey et al., 1992; Isaacson et al., 1992; Darian-Smith and Gilbert, 1994; Florence and Kaas, 1995).

There are several possible explanations to reconcile the striking decline in growth and growth-associated proteins with the extensive functional and structural plasticity in the adult nervous system. One proposal has been that axon remodeling in adults is restricted to specific subpopulations of neurons in which expression of major growth cone components persists throughout adult life (Skene and Willard, 1981b; Benowitz and Routtenberg, 1987; de la Monte et al., 1989). In fact, recent evidence shows that maintained expression of one of these genes in transgenic mice can enhance spontaneous axon sprouting by adult neurons (Aigner et al., 1995). It also has been suggested that axonal growth by adult neurons requires reexpression of growth cone components or other genes commonly expressed during development but suppressed in the majority of mature neurons (Bendotti, 1991). In some cases, axonal sprouting is indeed accompanied by reinduction of genes ordinarily associated with developmental axon growth (Represa et al., 1993; Bendotti et al., 1994; Mearow et al., 1994). Reinduction of these developmentally expressed genes, however, is most strikingly correlated with regenerative growth of long axons after peripheral nerve injury (Skene, 1989). Similar reinduction of growth-associated genes has been correlated with the ability of subsets of CNS neurons to regenerate long axons through peripheral nerve grafts in adult mammals (Doster 
et al., 1991; Schaden et al., 1994; Tetzlaff et al., 1994). It remains unclear, however, whether reexpression of any of these genes is essential for axon growth. Growth or remodeling of axons could be mediated entirely by genes expressed in the majority of mature neurons, without the need for re-activation of developmentally regulated growth cone components. Indeed, recent studies have suggested that proteins involved in synaptic transmission may also participate in membrane trafficking for axon growth (Feany and Buckley, 1993; Osen-Sand et al., 1993; Ferriera et al., 1994). Finally, distinct forms of axonal growth and remodeling may depend on different patterns of gene expression. In any case, determining the roles of individual gene products would be simplified by determining the extent to which axotomy-induced gene expression as a whole affects competence for axon growth.

Cultures of dissociated adult rat dorsal root ganglia (DRG) allowed us to determine the growth capabilities of individual adult neurons in the presence and absence of changes in gene expression elicited by nerve injury. These neurons support vigorous axon regeneration and reexpression of several growth-associated genes after peripheral nerve injury (Hoffman, 1989; Miller et al., 1989; Schreyer and Skene, 1991; Verge et al., 1992; Weise et al., 1992; Moskowitz et al., 1993; Mearow et al., 1994). Axonal sprouting by uninjured DRG neurons also has been demonstrated (Diamond et al., 1987; Florence and Kaas, 1995), although it is not known which subpopulations of DRG neurons are capable of this type of sprouting or the circumstances under which it can be evoked (Florence and Kaas, 1995).

Here we show that fully mature DRG neurons can support distinct modes of axon extension. Our results provide strong evidence that these modes rely on different patterns of gene expression. DRG neurons are able to extend highly branched arborizing neurites before axotomy-induced changes in gene expression and do so more robustly in response to exogenous neurotrophins and other soluble factors. However, a discrete period of new transcription after peripheral axotomy is critical in order for DRG neurons to support the rapid extension of long, sparsely branched axons. Furthermore, our results indicate that the switch from "arborizing" to "elongating" growth after peripheral axotomy is stimulated by the interruption of retrogradely transported signals activated through interactions of axons with peripheral targets. In addition, we demonstrate that central root injury does not produce the same cellular response.

\section{MATERIALS AND METHODS}

Standard DRG cultures. All chemicals were purchased from Sigma (St. Louis, MO) unless indicated otherwise. L4 and L5 ganglia were removed from adult male rats, snipped open with microdissecting scissors, and then placed in ice cold Gibco-BRL F14 medium (Life Technologies, Grand Island, NY) containing N1 additives (as described in Bottenstein and Sato, 1979). After being rinsed three times in F14+N1, the ganglia were placed $\mathrm{F} 14+\mathrm{N} 1$ containing $5000 \mathrm{U} / \mathrm{ml}$ type XI collagenase for 90 min at $37^{\circ} \mathrm{C}, 5 \% \mathrm{CO}_{2}$, and then dissociated gently with $16-20$ passages through a flamed Pasteur pipette. Type SII trypsin was added to 0.5 $\mathrm{mg} / \mathrm{ml}$ for $15 \mathrm{~min}$. The following items were added during the last $5 \mathrm{~min}$ : EDTA (1 mM), soybean trypsin inhibitor $(100 \mu \mathrm{g} / \mathrm{ml})$, and DNase I ( 80 $\mu \mathrm{g} / \mathrm{ml}$ ). Cells were washed twice by resuspension and centrifugation and then appropriately diluted in F14 medium containing 10\% horse serum. For standard cultures, $800-1200$ neurons were plated onto $12 \mathrm{~mm}$ round, glass coverslips precoated with $50 \mathrm{mg} / \mathrm{ml}$ poly-L-lysine (overnight at $37^{\circ} \mathrm{C}$ ), followed by $10 \mathrm{mg} / \mathrm{ml}$ laminin (UBI, Lake Placid, NY; overnight at $4^{\circ} \mathrm{C}$ ), and placed in a $37^{\circ} \mathrm{C}, 5 \% \mathrm{CO}_{2}$ incubator.

Modified DRG cultures. The effect of secreted substances and cell contact on neuritic growth by naive neurons was assayed by plating $2400-4800$ neurons per coverslip instead of $800-1200-\sim 4$ times the standard concentration of cells. Schwannoma-conditioned medium was obtained from cultures of D1 schwannoma cells (Pfeiffer et al., 1972) grown for 1 week to near confluence in DMEM containing $10 \%$ horse serum (Life Technologies). Conditioned medium was diluted to $50 \%$ in standard DRG culture medium. Other cultures were exposed to $2.5 \mathrm{~S}$ nerve growth factor (NGF; Boehringer Mannheim, Mannheim, Germany; $50 \mathrm{ng} / \mathrm{ml}$ ) beginning $20 \mathrm{~min}$ after plating. The influence of substratum was examined by comparing growth on polylysine only, on polylysine and laminin, or on a confluent layer of D1 schwannoma cells.

Sciatic nerve lesions. Adult rats were anesthetized by intraperitoneal injection of $0.15 \mathrm{ml} / 100 \mathrm{gm}$ ketamine followed by $0.15 \mathrm{ml} / 100 \mathrm{gm} 15 \%$ chloral hydrate. The left sciatic nerve was exposed at the hip by blunt dissection and crushed using fine jewelers forceps. This procedure disrupts $\sim 70-80 \%$ of the axons emerging from L4 and L5 ganglia (Himes and Tessler, 1989). Rats were allowed to survive for 2-7 d, and then DRGs were removed and cultured as described above.

Colchicine-releasing sciatic nerve cuffs. A 10\% solution of Elvax-p40 in methanol (DuPont NEN, Wilmington, DE) containing $3 \mathrm{mg} / \mathrm{ml}$ colchicine was poured into $22 \times 22 \mathrm{~mm}$ molds that had been frozen on dry ice. The thin sheets of quick-frozen Elvax were placed at $-80^{\circ} \mathrm{C}$ overnight to set and then stored at $4^{\circ} \mathrm{C}$ until used. Strips $(3 \mathrm{~mm}$ wide) were cut from these sheets and wrapped gently but snugly around the exposed sciatic nerves of anesthetized rats, and the ends were sealed with Superglue. Incisions were closed, and after $2 \mathrm{~d}$ DRGs were removed and cultured as described above.

Dorsal root lesions. The dorsal roots carrying central branches of L4 and L5 DRG neurons were exposed and crushed with fine jewelers forceps $\sim 1$ $\mathrm{cm}$ from the ganglia. Animals were killed after $48 \mathrm{hr}$ or 1 week. DRGs were dissociated and plated under standard culture conditions for $16 \mathrm{hr}$. At this time, the cultures were fixed and scored for arborizing and elongating processes as described below.

Visual and quantitative analysis of neurite outgrowth. Cultures were fixed with $4 \%$ paraformaldehyde and frequently visualized by immunoperoxidase staining (Vector Laboratories, Burlingame, CA) using monoclonal antibodies to the neuronal markers GAP-43 (Schreyer and Skene, 1991), MAP-2 (Sigma), or neurofilament H (Sigma). The percentage of all neurons with neurites longer than one cell diameter was determined by counting using differential interference contrast microscopy at $40 \times$ magnification. Unstained cultures were generally counted in parallel using phase microscopy. Quantitative analysis of neurite length and number of branch points per neurite was carried out on fixed cultures displayed on a video monitor. The longest processes from each cell were chosen for measurement. For Figures 6 and 7, the number of branches and total length were determined for 30 neurons of each condition (pooled from 3 separate experiments) and a scatter plot was generated as shown in Figure 4. Neurons with processes that fell above a line representing 1.5 branches per $100 \mu \mathrm{m}$ were categorized as arborizing, and those below were characterized as elongating.

Mixing of naive and pre-axotomized cultures. Approximately one-tenth of the cells from a naive ganglion were incubated for $1 \mathrm{hr}$ in suspension with the lipophilic dye DiI (Molecular Probes, Eugene, OR). Previously axotomized neurons were labeled in a separate tube. Meanwhile, the remainder of the naive and pre-axotomized cells were plated separately under standard conditions. The DiI-labeled, naive neurons were washed several times and then dispersed onto unlabeled pre-axotomized cultures. Similarly, DiI-labeled pre-axotomized neurons were washed and dispersed onto unlabeled naive cultures. After $16 \mathrm{hr}$, the percentage of labeled neurons exhibiting arborizing or elongating neuritic morphologies was determined.

Transcriptional inhibition. The synthesis of mRNA was inhibited permanently by the addition of $\alpha$-amanitin (Lindell et al., 1970) or transiently by the addition and washout of 5,6-dichlorobenzimidazole riboside (DRB) (Tamm and Sehgal, 1978), both potent inhibitors of RNA polymerase II. DRB-treated and untreated cultures were fixed with $4 \%$ paraformaldehyde and scored for neurite growth as described. DRB is reported to block mRNA synthesis specifically within minutes of application (Tamm and Sehgal, 1978). We measured the effect DRB on mRNA synthesis in DRG cultures by incubating naive cultures exposed to increasing concentrations of the drug with $\left[{ }^{3} \mathrm{H}\right]$ uridine for $1 \mathrm{hr}$. Total RNA was isolated, and newly synthesized RNA was quantified by scintillation counting of ethanol-precipitable radioactivity. At the dose used in experiments described in this paper $(80 \mu \mathrm{M})$, RNA synthesis was reduced by $>95 \%$. To assess the effects of DRB treatment on overall protein synthesis, cultures were incubated with or without DRB for $12 \mathrm{hr}$ and then the DRB-containing medium was exchanged for fresh medium. After $10 \mathrm{hr}$, cultures were incubated for $2 \mathrm{hr}$ in medium containing 
$\left[{ }^{35}\right.$ S $]$ methionine. Labeled proteins were separated by SDS-PAGE and visualized by autoradiography.

\section{RESULTS}

\section{Genes constitutively expressed in adult neurons can support robust neurite growth}

To analyze the growth capabilities of adult neurons, we examined axon outgrowth from DRG neurons acutely isolated from adult rats and cultured under conditions known to support neuritic growth from these cells (Lindsay, 1988). We first compared the onset of outgrowth from neurons that had undergone no treatment before removal from the animal (naive neurons) with growth from cells that had responded in vivo to a peripheral nerve injury (pre-axotomized), which activates expression of growthassociated genes and other cell body responses over a period of days after injury (Hoffman, 1989; Miller et al., 1989; Schreyer and Skene, 1991; Verge et al., 1992; Moskowitz et al., 1993; Mearow et al., 1994). As anticipated from previous studies of other mature primary neurons (Landreth and Agranoff, 1976; Argiro and Johnson, 1982; Collins and Lee, 1982), the majority of naive DRG neurons failed to extend neurites during the first day in culture, whereas pre-axotomized cells extended processes within hours after plating (Fig. 1).

What was not anticipated from previous work was the extension of neurites from $\sim 20-25 \%$ of naive DRG neurons during the first day in culture (Fig. 1). Genes constitutively expressed in vivo are sufficient to support this early outgrowth, because it was unaltered when cells were cultured in the continuous presence of either DRB (Fig. 2) or $\alpha$-amanitin (not shown), both potent inhibitors of new mRNA synthesis (Lindell et al., 1970; Tamm and Segal, 1978).

Competence for this early growth is not restricted to a subset of DRG neurons that maintain persistent expression of any unique set of genes, because plating at higher cell density (increasing the number of neurons, Schwann cells, and fibroblasts) stimulated early neurite outgrowth from nearly $70 \%$ of naive neurons, even in the continued presence of DRB (Fig. 2). Similarly, exuberant neuritic growth could be induced by soluble factors. Medium conditioned by a schwannoma cell line (Pfeiffer and Wechler, 1972) elicited acute outgrowth from $>40 \%$ of naive cells, as did the addition of NGF, one of several neurotrophins and cytokines produced by Schwann cells (Kimura et al., 1990; Matsuoka et al., 1991; Wanaka et al., 1993; Richardson, 1994). In both cases, stimulated neurite outgrowth occurred in the absence of new mRNA synthesis (Fig. 2). Our results indicate that genes constitutively expressed in the majority of intact adult DRG neurons are sufficient to support neurite growth in response to some environmental cues.

\section{Altered outgrowth after axon injury in vivo}

Although acutely cultured naive DRG neurons have the capacity to support neurite extension, previous peripheral axotomy dramatically alters the type of neurites these cells extend during the first day in culture. In contrast to the extensive branching and modest length of neurites extended by naive neurons (Fig. $3 A$ ), neurites extended by previously axotomized neurons tended to be very long, and they branched rarely (Fig. $3 B$ ). These long neurites often fasciculated with one another (Fig. $1 A$ ), a behavior rarely observed in naive cultures during the first day after plating. The growth cones were typically tapered, with few filopodia (Fig. 3B), and advanced rapidly over the laminin substrate. The rate of advance for individual growth cones varied over time but could
A
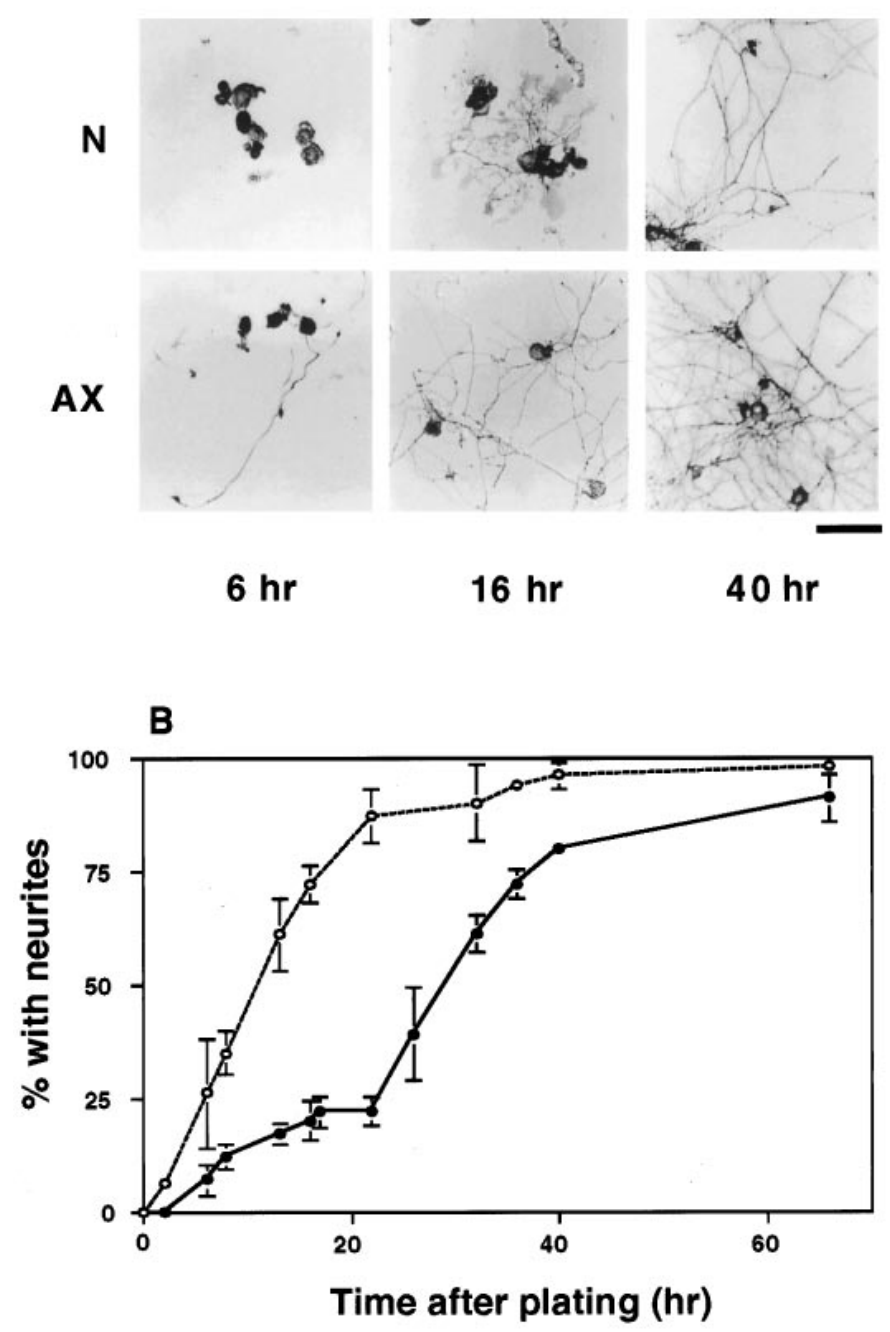

Figure 1. Distinct time courses of neurite outgrowth from naive and previously axotomized neurons. Neurons from L4 and L5 DRG of adult rats were dissociated and plated under standard conditions, as described in Materials and Methods. Naive neurons from uninjured animals $(N)$ and pre-axotomized neurons the peripheral axons of which had been injured in vivo 1 week earlier $(A X)$ were observed over time in culture. $A$, Neurons and neurites in typical cultures photographed 6,16 , and $40 \mathrm{hr}$ after plating. Immunoperoxidase staining for GAP-43 labels all neurons and their neurites to varying degrees. Scale bar, $100 \mu \mathrm{m}$. $B$, Time course showing the percentage of neurons in naive cultures (solid line, filled circles) and pre-axotomized cultures (dashed line, open circles) that had extended neurites by the indicated times after plating. Each time point represents the mean $\pm \mathrm{SD}$ of at least three to seven separate experiments, with duplicate cultures in each experiment.

reach $1.0 \mathrm{~mm} / \mathrm{hr}$ (Hess et al., 1993), often producing neurites reaching 1-3 $\mathrm{mm}$ in length during the first day in culture. The much shorter neurites emerging from naive DRG neurons during the first day after plating often terminated in large, complex growth cones (Fig. 3A). Preliminary video analysis indicates that, by $12-16 \mathrm{hr}$ after the initial plating, elongation rates rarely exceeded $10 \mu \mathrm{m} / \mathrm{hr}$ (our unpublished observations).

Quantitation of the length and branching of individual neurites shows that the processes extended by naive neurons and preaxotomized neurons during the early phase of outgrowth define two distinct modes of axon growth (Fig. $4 A, C$ ). For this analysis, we scored only neurites that could be traced over their entire 

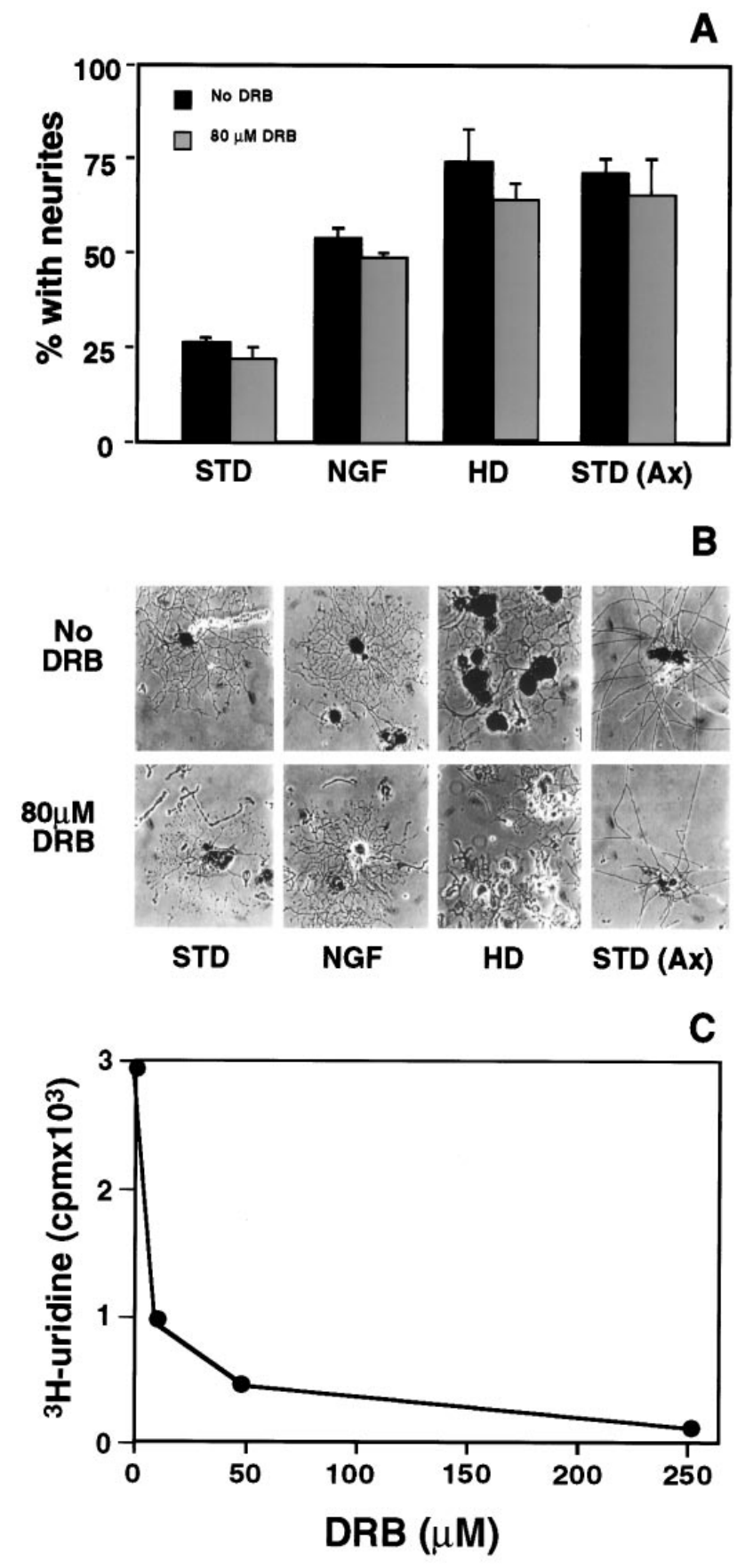

Figure 2. Genes commonly expressed in intact adult neurons are sufficient to support robust axon outgrowth. $A$, The percentage of neurons with neurites $16 \mathrm{hr}$ after plating was determined in transcriptionally active cultures (black bars) and for cultures in which mRNA synthesis was blocked by $80 \mu \mathrm{M}$ DRB, a potent inhibitor of RNA polymerase II (gray bars). Only $20-25 \%$ of naive neurons extended neurites by $16 \mathrm{hr}$ under standard conditions ( $S T D$ ), but the addition of $N G F$ to the medium or use of medium condition by schwannoma cells (not shown) stimulated growth from more neurons during the same interval. Plating at $4 \times$ the standard density $(H D)$ had a more pronounced effect. Neuritic growth stimulated by these conditions was not inhibited by continuous exposure to DRB. Neurite extension from neurons axotomized 1 week earlier by sciatic nerve crush in vivo [STD $(A x)]$ was also unaffected by DRB. Data represent the mean \pm SD for four separate experiments with duplicate cultures in each experiment. $B$, Representative neurite-bearing neurons at $16 \mathrm{hr}$ after plating in the absence (top row) or presence (bottom row) of DRB. C, DRB effectively inhibits mRNA synthesis in DRG cultures. At the doses used in these experiments $(80 \mu \mathrm{M})$, uptake of $\left[\mathrm{H}^{3}\right]$ uridine is inhibited $>90 \%$. length. Because very long neurites in pre-axotomized cultures overlap and fasciculate with other processes, the longest processes in these cultures are under-represented in the quantitative analysis. Nonetheless, quantitation of individual neurites shows a profound difference in the characteristics of growth by naive and pre-axotomized neurons. Those processes of pre-axotomized neurons that could be traced were frequently $>500 \mu \mathrm{m}$ in length, with very few if any branches per neurite. In contrast, individual neurites extended by a subset of naive neurons under standard conditions branched an average of seven times but rarely exceeded $100 \mu \mathrm{m}$ in length.

To examine the characteristics of neurites extended by the majority of naive neurons, we analyzed processes induced by high-density plating (Fig. 4A) and addition of NGF or schwannoma-conditioned medium (Fig. 4B). Neurites extended under those conditions were somewhat longer than in the absence of exogenous growth factors, but they remained shorter than the long axons characteristic of pre-axotomized cells. Moreover, the absolute number of branch points per neurite remained high. The number of branch points and length of neurites $16 \mathrm{hr}$ after plating were not affected by continuous exposure to the transcription inhibitor DRB (Fig. 4D).

Although the arborizing and elongating neurites differ in several characteristics (see above), the spatial frequency of branching provides a simple and objective measurement for distinguishing the arborizing outgrowth characteristic of naive DRG neurons from the elongating outgrowth induced after axon injury in vivo. Graphic analysis shows that all neurites extended during the first $16 \mathrm{hr}$ by naive DRG neurons, under any culture conditions tested, cluster above a line corresponding to a branching frequency of 1.5 branch points per $100 \mu \mathrm{m}$. Neurites with a much lower frequency of branching arise only from cells that have responded to a previous nerve injury (Fig. $4 E$ ). It is notable that a small number of neurons from these pre-axotomized ganglia extend neurites that overlap in branch frequency with those of naive neurons (Fig. $4 E)$. This may reflect the fact that the sciatic nerve lesions used for these studies interrupts the axons of only 70-80\% of neurons in the L4 and L5 DRG (Himes and Tessler, 1989). For subsequent analysis, we will include in the "arborizing" category all neurons for which the branching frequency of the longest neurite is 1.5 per $100 \mu \mathrm{m}$ or greater. Neurons with a lower frequency of branching will be scored as "elongating."

To determine whether an unspecified factor in pre-axotomized cultures or an intrinsic change in injured neurons was prompting the growth of elongating neurites, a small number of naive neurons were labeled with the fluorescent dye DiI and then dispersed onto a bed of newly plated cells from pre-axotomized DRG harvested at the same time. By $16 \mathrm{hr}$ after plating, $<10 \%$ of the labeled neurons had elongating neurites, demonstrating that the environment of a pre-axotomized culture was not sufficient to elicit an elongating mode of growth from naive neurons. In the converse experiment, DiI-labeled neurons from pre-axotomized ganglia readily extended elongating axons in the environment of naive DRG cultures. Furthermore, the distinction between arborizing and elongating modes of growth does not lie simply in the responsiveness of cells to the laminin substrate. Even after being plated for $16 \mathrm{hr}$ on a confluent layer of schwannoma cells (Pfeiffer and Wechsler, 1972), <10\% of naive neurons had extended elongating processes, whereas $70 \%$ of pre-axotomized neurons plated onto poly-D-lysine alone had done so (data not shown). 
A
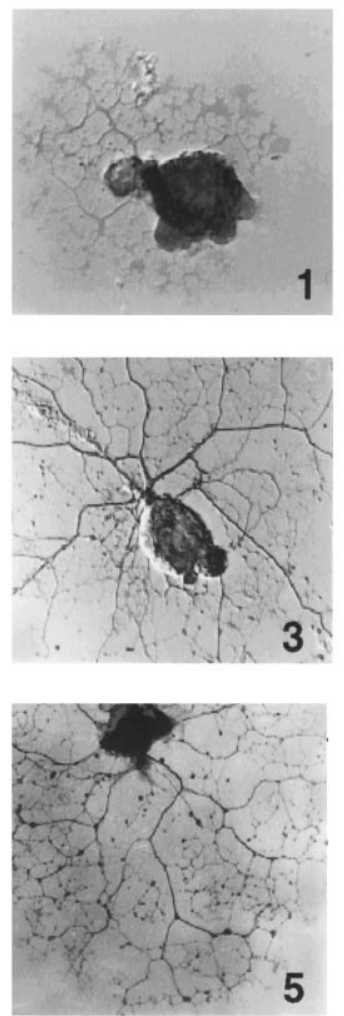
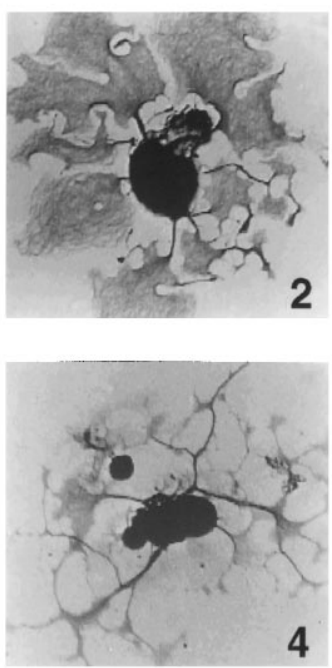

4

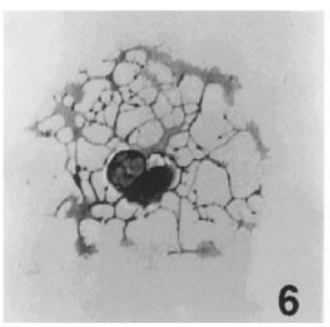

B
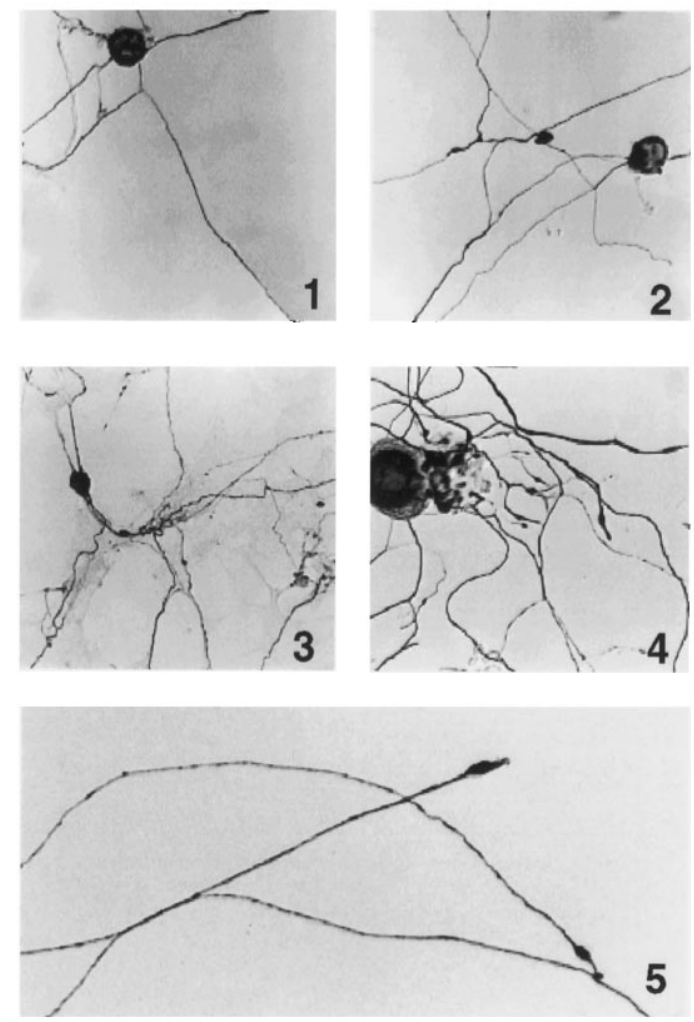

Figure 3. Naive and pre-axotomized neurons extend different types of neurites in acute cultures. $A$, Naive adult DRG neurons after 16 hr under standard plating conditions extend neurites that are highly branched and extend over a limited radius, terminating in large, palmate growth cones with numerous filopodia. $B$, Neurites in $16 \mathrm{hr}$ cultures from previously axotomized rats $(1,2,4,5)$ or in $40 \mathrm{hr}$ cultures from naive rats (3) branch much less frequently, often exceed 1-2 $\mathrm{mm}$ in length, and tend to fasciculate with other processes. Growth cones are typically tapered with few filopodia (5). Immunoperoxidase labeling with antibodies to major neuronal proteins stained all neurons to varying degrees and were often used to facilitate counting: GAP-43 ( $A$ : 1,2 , $5,6 ; B: 1-3)$, NF-H $(A: 4 ; B: 4)$, or MAP-2 $(A: 3)$. Scale bar, $75 \mu \mathrm{m}$.

\section{In vitro transition produces competence for elongation by naive neurons}

Removal and dissociation of naive adult DRG axotomize neurons, and we found that by the second day in culture, cells from naive DRG also began to extend processes that resembled the elongating axons of pre-axotomized neurons (Fig. 5). To follow the emergence of this elongating type of growth in naive cultures, neurons at various times after plating were scored for arborizing and elongating growth in two assays. Quantitation of a sample of neurons from each culture was used to determine the percentage of cells with arborizing and elongating processes on the basis of branching frequency. To avoid any effects of sample bias, we also used visual inspection to score all cells in each culture dish on the basis of neurite length, branching frequency of all processes, growth cone morphology, and fasciculation. Both visual inspection (Figs. 1, 3) and quantitative analysis (Figs. 5, 6) show that neurites with a characteristic elongating morphology first emerge in naive DRG cultures beginning $\sim 24 \mathrm{hr}$ after cells are dissociated and plated. The percentage of neurons with elongating axons increases sharply, followed by a slow decline in the number of arborizing cells. By $48 \mathrm{hr}$ after plating, a majority of neurites are of the elongating type. Figure $6 A$ shows that the curve representing the onset of elongation in naive cultures is similar to that derived from pre-axotomized cultures but is shifted to the right by $\sim 20 \mathrm{hr}$.

Analysis of individual neurons from naive ganglia over time in culture demonstrated that change in the percentage of neurons with arborizing and elongating processes does not reflect differential cell survival or death (Table 1). To follow the fates of individual cells, we located and photographed 60 neurons in naive DRG cultures $12 \mathrm{hr}$ after plating and then incubated the cultures for an additional $24 \mathrm{hr}$. Of 25 cells with no discernible neurites at $12 \mathrm{hr}$ after plating, all but $7(28 \%)$ could be relocated after $36 \mathrm{hr}$ in culture. Of the relocated cells, $56 \%$ had extended axons with an elongating morphology, $5 \%$ had extended arborizing neurites, and the remaining cells $(39 \%)$ appeared viable but had not yet extended processes. Of 35 cells with arborizing neurites at $12 \mathrm{hr}$ after plating, all but $6(17 \%)$ could be relocated after $36 \mathrm{hr}$ in culture. Of these, $45 \%$ had extended elongating axons and $10 \%$ retained typical arborizing neurites. The remaining $45 \%$ retained some neurites with an arborizing morphology but also displayed one or more sparsely branched processes that extended beyond the halo of highly branched neurites. These cells may represent an intermediate stage in a transition from arborizing to elongating growth. These results indicate that the emergence of elongating axons from naive DRG neurons, beginning $24 \mathrm{hr}$ after dissociation 
A
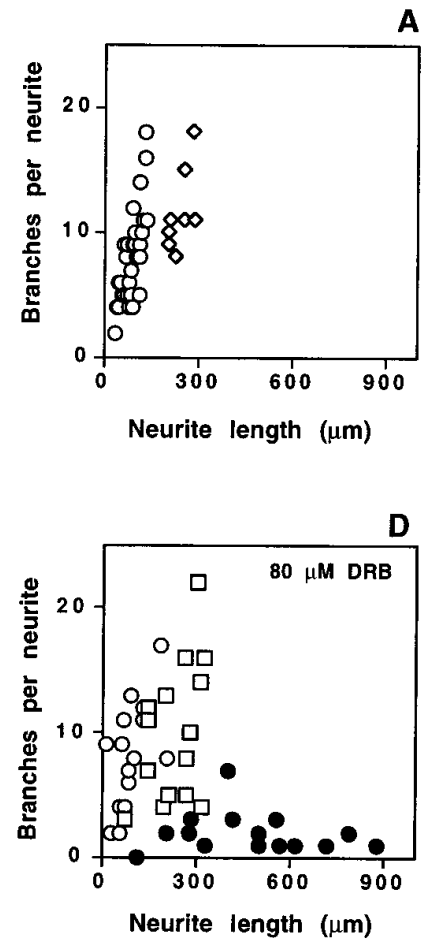

B

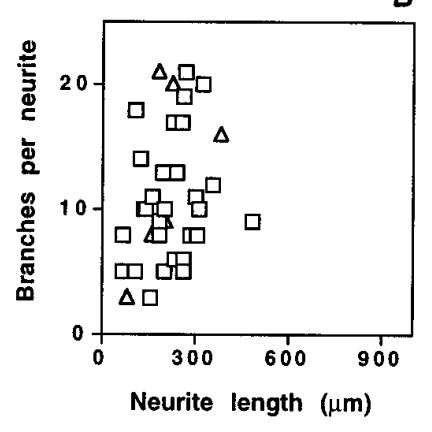

$\mathbf{E}$

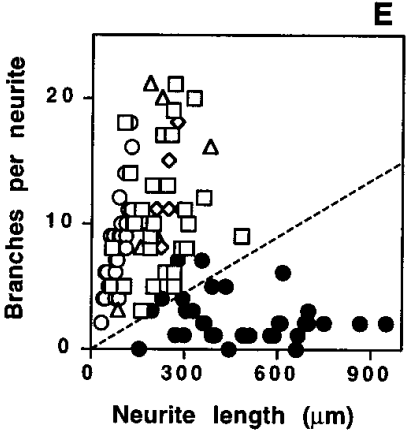

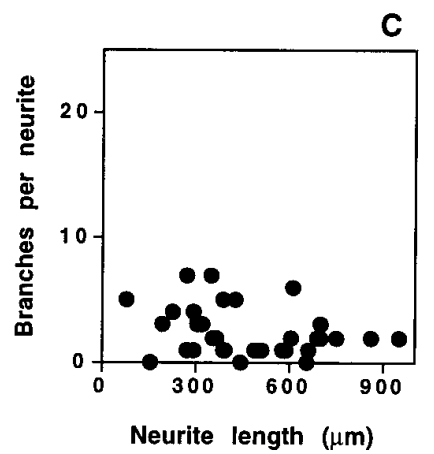

C

1.5 branches/100 $\mu \mathrm{m}$

Figure 4. Neurites of naive and pre-axotomized neurons define two distinct modes of axon growth. Previous axotomy in vivo influenced the growth characteristics of DRG neurons, prompting the extension of longer neurites with fewer branches during the first day in culture. The length and number of branch points were determined for the longest neurite extended by randomly selected DRG neurons from three separate experiments in which cultures had been fixed $16 \mathrm{hr}$ after plating. Open symbols represent individual neurons from naive ganglia; filled symbols those from pre-axotomized ganglia. $A$, Naive cells plated under standard conditions (circles) or at high density, which promotes outgrowth from a majority of neurons (diamonds). B, Naive neurons cultured in the presence of schwannoma-conditioned medium (triangles) or NGF (squares). $C$, Pre-axotomized neurons plated under standard conditions. $D$, Inclusion of the transcription inhibitor DRB during dissociation and plating had no effect on length and branching. $E$, Data from $A-C$ plotted on a single graph. All neurites extended by naive neurons, regardless of culture conditions, exhibit a branching frequency $>1.5$ branches per 100 $\mu \mathrm{m}$ (dotted line). This line, therefore, serves as a simple objective criterion for categorizing neurons. For subsequent quantitative analysis, data points that fall above this line will be scored as "arborizing" and those that fall below the line will be scored as "elongating."

and plating, reflects a transition in the growth characteristics of individual neurons rather than differential survival of a subpopulation of cells competent for elongation. Elongation, furthermore, occurs both from the subset of neurons that extend arborizing neurites during the first $12 \mathrm{hr}$ under standard culture conditions and from the majority of cells that initially fail to extend processes under those conditions.

\section{Elongating axon growth requires a period of gene transcription after axotomy}

The ability of naive DRG neurons to carry out in vitro the transition between growth modes induced by sciatic nerve lesion provides an experimentally accessible system for analyzing the critical molecular events in that transition. We used DRB, the reversible inhibitor of RNA polymerase II, to determine whether the onset of neuronal competence for elongating growth requires new gene transcription after axotomy. Naive DRG neurons were plated under standard culture conditions and exposed transiently to DRB for the first $12 \mathrm{hr}$ after plating. The percentage of neurons with elongating axons was then determined at 40 and $66 \mathrm{hr}$ after plating by visual categorization of all of the neurons in each culture (Fig. $7 A$ ) and by quantitative analysis of a sample of the cells (Fig. $7 B$ ). When transcription was prevented during the first $12 \mathrm{hr}$ in culture, the emergence of elongating axons was delayed dramatically. The number of neurons with elongating axons remained low until at least $40 \mathrm{hr}$ after plating and then increased to near control levels by $66 \mathrm{hr}$ (Fig. 7A). As illustrated in Figure $7 B$, this transient inhibition of axon elongation can be accounted for by a simple displacement in the onset of elongation by $\sim 16 \mathrm{hr}$. Biochemical analysis indicated that cells treated with DRB for the first $12 \mathrm{hr}$ in culture showed no gross alterations in protein synthesis by $24 \mathrm{hr}$ after plating, just before the onset of elongation in control cultures (Fig. 7C).

Interestingly, when naive DRG neurons were allowed to synthesize new mRNA for $12 \mathrm{hr}$ after plating, and then exposed to DRB for $12 \mathrm{hr}$, there was a less dramatic reduction in the number of elongating neurites at the $40 \mathrm{hr}$ time point; by $24 \mathrm{hr}$ after plating, cells no longer required ongoing transcription to support axon elongation (Fig. $7 A, B$ ). Similarly, neurons pre-axotomized in vivo are able to support elongating axon outgrowth in the continuous presence of DRB for $16 \mathrm{hr}$ after plating (Fig. 2). The results indicate that a finite period of new transcription after axotomy is essential in order for naive DRG neurons to gain competence for the elongating mode of axon growth.

\section{Regulation of growth mode by target-dependent retrograde signals}

The transition from arborizing to elongating growth can be triggered in DRG neurons by axon interruptions resulting from removal and dissociation of a ganglion or from peripheral nerve injury in vivo. This implies that signals conveyed along axons to neuron cell bodies can regulate the growth mode supported by DRG neurons. To explore the nature of these signals, we used the microtubule-depolymerizing agent colchicine to block axonal 

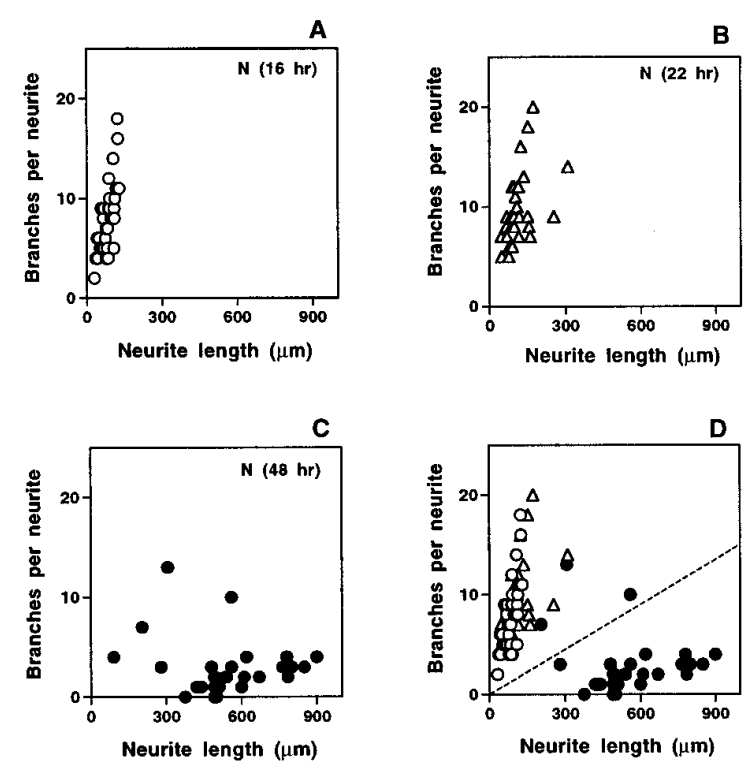

Figure 5. Neurites observed at later times in cultures from naive animals resemble those extended early by previously axotomized neurons. Randomly selected naive neurons from three separate naive cultures at different times were analyzed for length and number of branch points of their longest neurite. High frequency of branching and limited length persisted through 16 and $22 \mathrm{hr}(A, B)$, but by $48 \mathrm{hr}(C)$ neurites were typically longer with fewer branches, resembling neurites in $16 \mathrm{hr}$ cultures from preaxotomized ganglia. When plotted together $(D)$, the data segregate on either side of the same line used in Figure 4, with neurites from 16 and 22 $\mathrm{hr}$ cultures falling above the line and the majority of those from $48 \mathrm{hr}$ cultures falling below the line.

transport in DRG axons. Colchicine was applied to the sciatic nerve by encircling the nerve with a permeable plastic cuff impregnated with the drug. Two days later, DRG neurons were removed and assayed for their ability to support arborizing and elongating outgrowth in our standard culture assay (16 hr after dissociation and plating).

Electron microscopy confirmed that axons in the nerve segment surrounded by the plastic cuff remained intact, although the depolymerization of microtubules produced a characteristic eccentricity in the shape of the axons (Fig. 8A). Application of colchicine to the sciatic nerve $1 \mathrm{hr}$ before a nerve crush had no effect on the ability of nerve injury to induce the in vivo transition to elongating growth (Fig. $8 B$ ). On the other hand, disruption of axonal transport in the absence of nerve injury was sufficient to induce a dramatic increase in the number of DRG neurons able to support axon elongation in vitro. Quantitative analysis of individual cells showed that the length and branching frequencies of axons from the colchicine pretreated neurons closely resembled the elongating axons from pre-axotomized cells (Fig. 8C). The

Table 1. Neurons that had not extended neurites by $12 \mathrm{hr}$ after plating, as well as those that had extended arborizing neurites, exhibited elongating neurites by $36 \mathrm{hr}$

\begin{tabular}{|c|c|c|c|c|}
\hline \multirow{2}{*}{$\begin{array}{l}\text { Status } \\
12 \mathrm{hr} \text { after } \\
\text { plating }\end{array}$} & \multirow{2}{*}{$\begin{array}{l}\text { Percent } \\
\text { relocated } \\
36 \mathrm{hr} \text { after } \\
\text { plating }\end{array}$} & \multicolumn{3}{|c|}{ Status $36 \mathrm{hr}$ after plating } \\
\hline & & No neurites & Arborizing & Elongating \\
\hline No neurites & $72 \%$ & $39 \%$ & $5 \%$ & $56 \%$ \\
\hline Arborizing & $83 \%$ & $0 \%$ & $55 \%$ & $45 \%$ \\
\hline
\end{tabular}
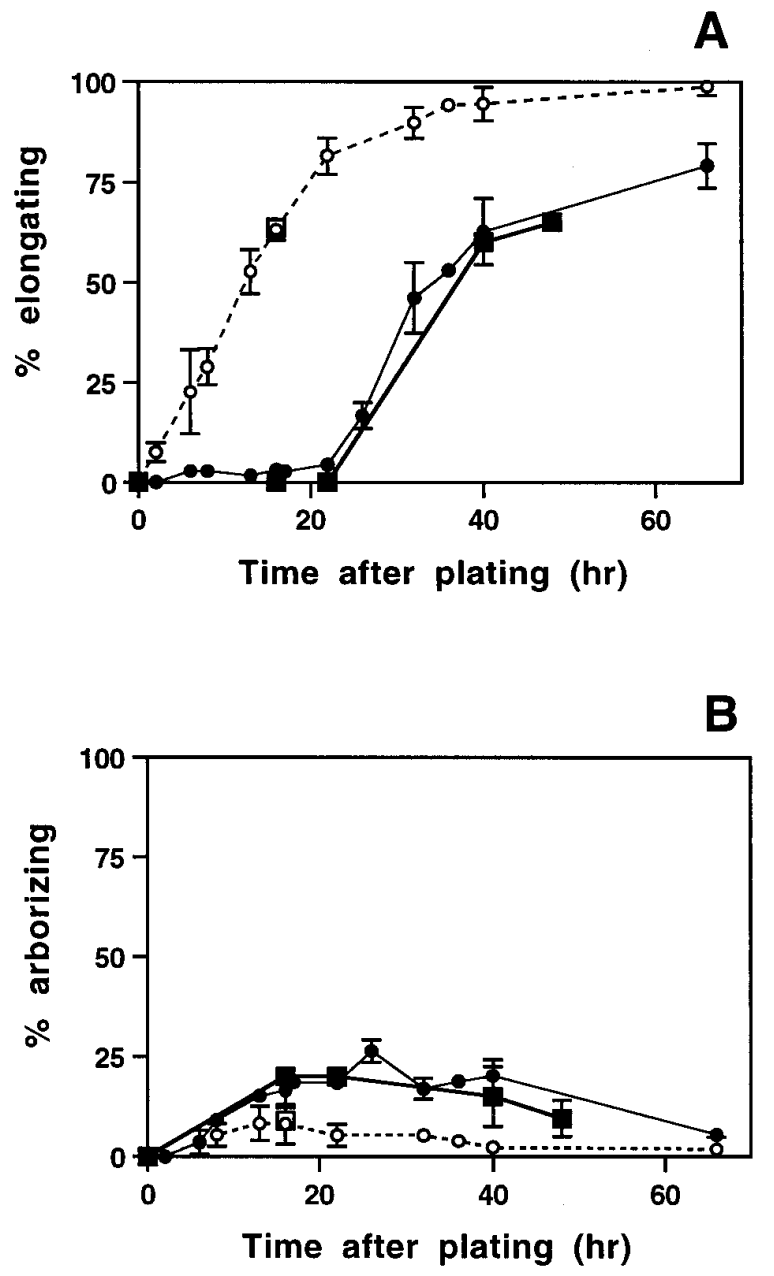

Figure 6. In vitro transition from arborizing to elongating growth by naive neurons. The percentage of naive and pre-axotomized neurons with elongating $(A)$ or arborizing $(B)$ neurites was determined at various times after plating, using visual inspection of all neurons in each culture (circles) or by quantitative analysis of neurite length and branching frequency for randomly selected neurons, as described in Figure $4 D$ (squares). Filled symbols represent cultures from naive ganglia, and open symbols are from pre-axotomized ganglia. Each visually derived time point (circles) represents the mean $\pm \mathrm{SD}$ of three to seven separate experiments, with duplicate cultures in each experiment. Time points derived from quantitative analysis include 480 randomly selected naive neurons pooled from three separate experiments (squares). The onset of elongating growth is delayed for $\sim 24 \mathrm{hr}$ in naive cultures, but the subsequent emergence of elongating axons parallels the initial outgrowth from pre-axotomized neurons. Arborizing growth plateaus near $20-25 \%$ and then declines as more neurons begin to exhibit the elongating morphology.

proportion of DRG neurons extending elongating axons after colchicine treatment in vivo was slightly lower than after sciatic nerve crush. This could result from incomplete or delayed inhibition of axonal transport in some axons in the interior of the sciatic nerve, or it could indicate that signals in addition to the disruption of axonal transport contribute to the regulation of elongating growth after nerve injury. The results show, however, that disruption of ongoing retrograde transport of signals in intact axons is sufficient to induce competence for elongating growth in many DRG neurons. This, in turn, implies that competence for elongation is chronically suppressed in the intact adult neurons by signals conveyed by retrograde axonal transport in peripheral axons.

To identify the source of these retrogradely transported signals, 

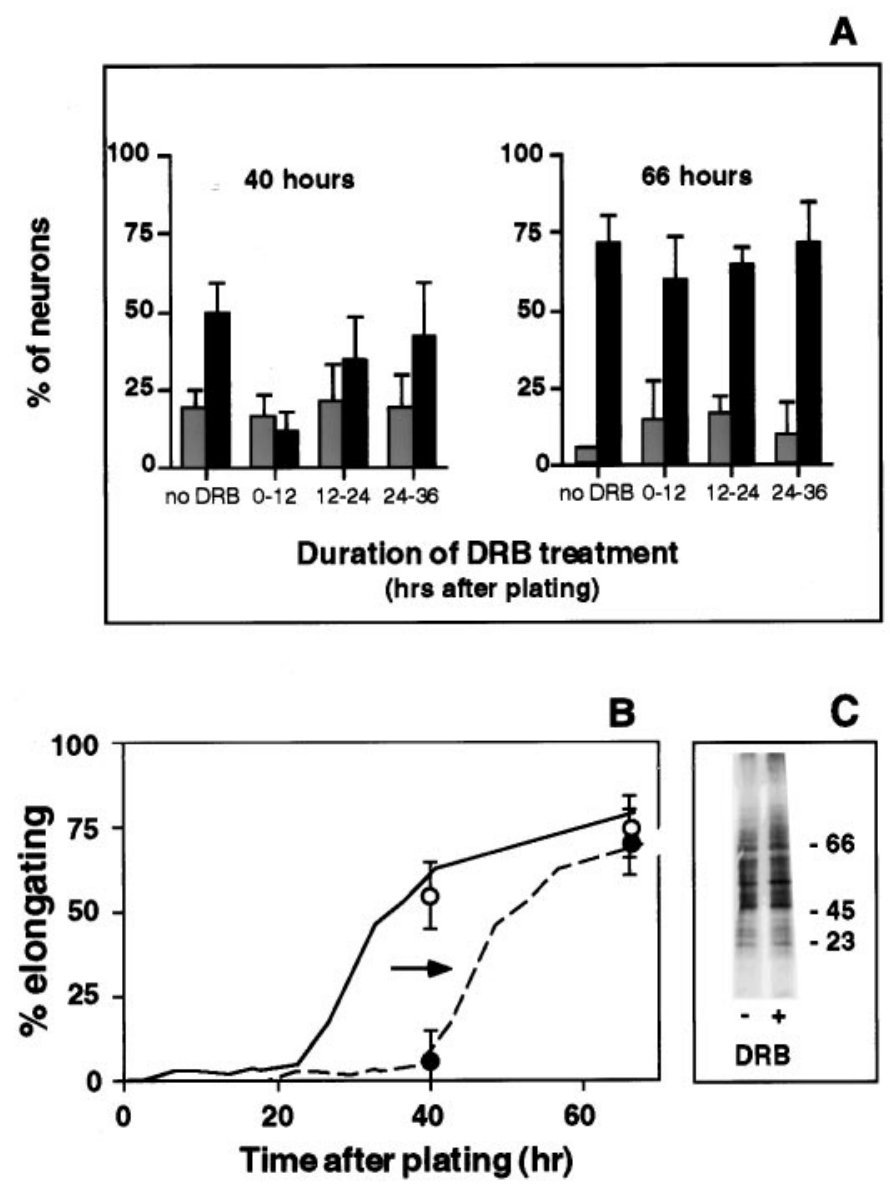

Figure 7. Onset of elongation from naive neurons requires a finite period of new gene transcription after plating. $A$, Naive DRG cultures were exposed to DRB, a reversible inhibitor of mRNA synthesis for the indicated intervals. Neurons in both DRB-treated and untreated cultures were fixed 40 and $66 \mathrm{hr}$ after plating and visually scored as arborizing (gray bars) and elongating (black bars). Early DRB treatment dramatically reduced the percentage elongating at $40 \mathrm{hr}$, but not at $66 \mathrm{hr}$. When transcription was blocked between 12 and $24 \mathrm{hr}$ after plating, the effect was less pronounced, and by $24 \mathrm{hr}$ after plating, neurons were no longer dependent on ongoing transcription to initiate and sustain neurite elongation. Bars represent the mean \pm SD from three separate experiments with duplicate cultures in each experiment. $B$, Estimate of delay produced by transient DRB treatment. The percentage of neurons with elongating neurites was rescored by quantitation of length and branching frequency. Filled circles represent neurons treated with DRB for the first $12 \mathrm{hr}$; open circles represent control neurons in untreated cultures. Each data point represents the mean \pm SD for three separate experiments (30 individual neurons). These data were then compared to the previously determined time course for the onset of elongation under standard conditions (solid curve, from Fig. $6 B$ ). To estimate the length of delay produced by transient DRB treatment, we displaced this curve to the right until it intersected with the data points for DRB-treated cultures. The result indicates that an initial exposure to DRB for $12 \mathrm{hr}$ produces a delay in the onset of elongating growth of $\sim 16 \mathrm{hr}$. $C$, The delay was not attributable to an overall decrease in protein synthesis, because transient DRB exposure for the first $12 \mathrm{hr}$ after plating did not grossly alter protein synthesis measured $12 \mathrm{hr}$ later, when elongating neurites begin to emerge in control but not in DRB-treated cultures.

we first performed crush lesions of the sciatic nerve at varying distances from neuronal cell bodies (Fig. 9A). The more proximal lesions (1.0-1.5 $\mathrm{cm}$ from the ganglia) remove a large part of the axon and disconnect cell bodies from signals arising along the length of the nerve and from peripheral targets. More distal lesions (5.0-5.5 $\mathrm{cm}$ from the ganglia) remove the influence of peripheral targets but leave a large portion of the axon and its associated Schwann cells in communication with the cell body. After 24, 48, or $72 \mathrm{hr}$, neurons were cultured as usual and assayed for elongating neurites $16 \mathrm{hr}$ after plating. We found that both proximal and distal lesions elicit competence for elongating growth in the majority of DRG neurons by $48 \mathrm{hr}$ after injury (Fig. $9 A$ ). The slightly lower number of elongating cells resulting from the more distal lesion is consistent with previous evidence that only $70 \%$ of neurons in the lumbar ganglia project axons to the more distal lesion site (Himes and Tessler, 1989; Schreyer and Skene, 1993). The results indicate that removal of peripheral targets is sufficient to induce competence for elongating growth in vivo. Although both proximal and distal lesions induce the transition to elongating growth in DRG neurons, onset of the response requires more time after the more distal injury (Fig. 9A). These findings are consistent with differences in time required to deplete transported molecules present in the proximal axon stumps at the time of injury.

When DRG axons are allowed to regenerate and restore contact with peripheral targets, their ability to support elongating growth in the $16 \mathrm{hr}$ tissue culture assay declines by 8 weeks after peripheral nerve injury (Fig. $9 B$ ). When regeneration and target reinnervation are disrupted, by transecting the nerve or by resecting a $5 \mathrm{~mm}$ segment of nerve, DRG neurons maintain competence for elongating growth at least 8 weeks after the injury (Fig. 9B). Together, the results indicate that competence for the elongating mode of axon growth is chronically suppressed in uninjured adult DRG neurons by retrogradely transported signals activated by interactions of axons with peripheral targets.

\section{Central and peripheral axotomy differentially affect growth competence}

In addition to its peripherally projecting branch, the axon of each DRG neuron extends a second branch through the dorsal root to innervate targets in the spinal cord or brainstem. Previous studies have shown that interruption of these centrally projecting axons induces only limited expression of some genes activated by peripheral injury (Wong and Oblinger, 1990; Jenkins et al., 1993) and fails to induce others (Schreyer and Skene, 1993; Chong et al., 1994). To test how central axotomy alters the growth competence of neurons, we assayed outgrowth from DRG cells 2 or $7 \mathrm{~d}$ after dorsal root injury. At either time after central axotomy, the total number of DRG neurons extending arborizing and elongating neurites under our standard assay conditions was increased compared to naive neurons (Fig. 10A). There was a small increase in the number of cells with arborizing processes. Most notably, the percentage of neurons with axons meeting the criteria for elongating growth was also elevated by central axotomy but remained far below the number observed after peripheral lesions.

Quantitative analysis of individual cells showed the axons extended by these centrally axotomized neurons did not segregate into two distinct populations corresponding to arborizing and elongating neurites. Rather, the distribution of growth characteristics for centrally axotomized neurons is intermediate between those of naive and peripherally axotomized cells (Fig. 10B). For the population as a whole, central axotomy produces a substantial reduction in branching and an increase in neurite length. Nonetheless, branching remains much more extensive than after peripheral axotomy, and a majority of neurons fail to extend processes longer than $300 \mu \mathrm{m}$. It is not yet clear whether those centrally lesioned cells that extend much longer axons represent a discrete subpopulation of DRG neurons or stochastic variation 


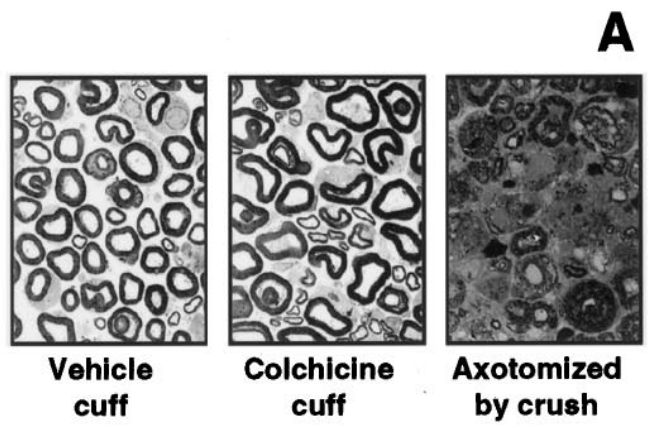

B
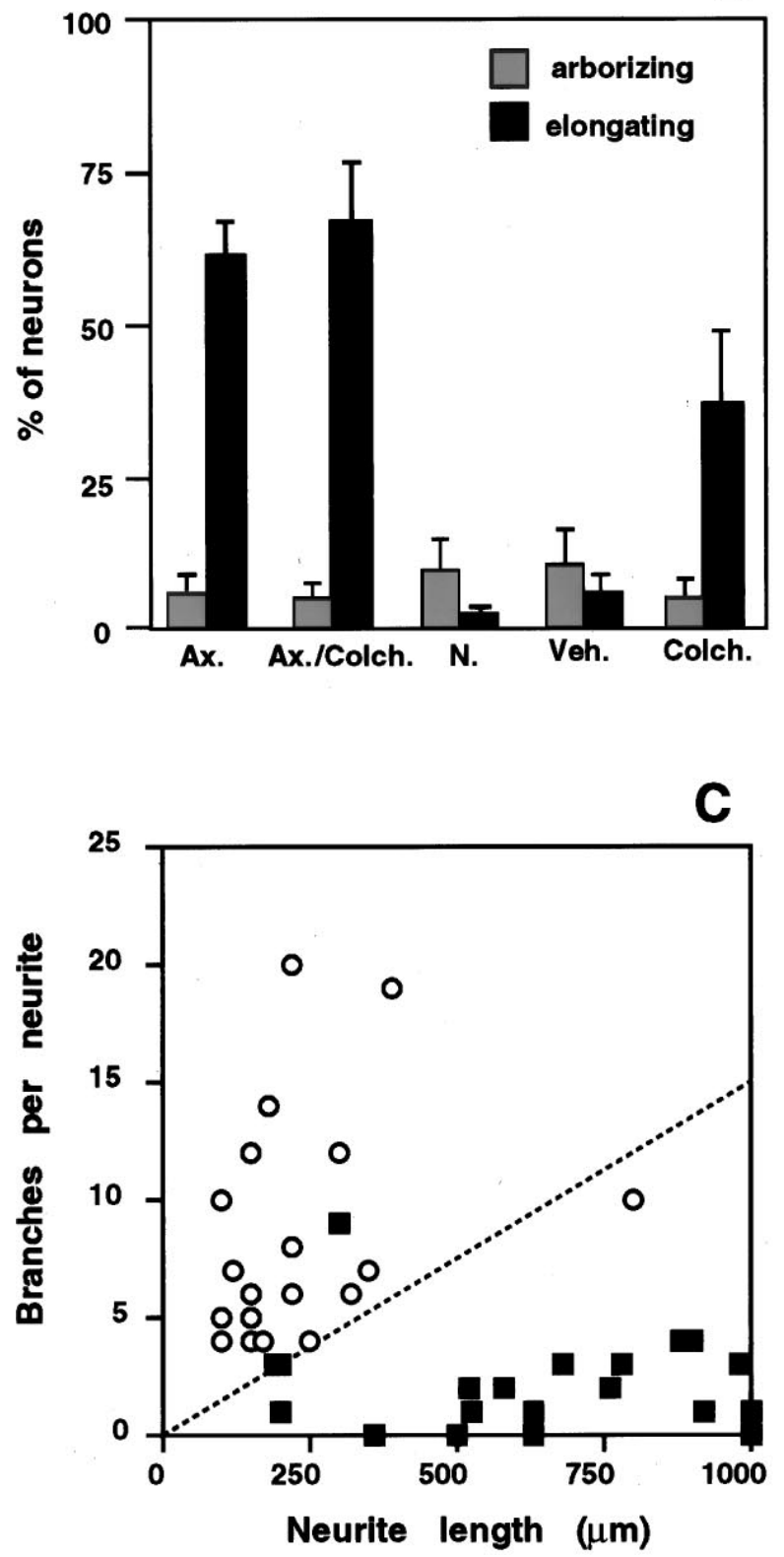

Figure 8. Disruption of axonal transport induces competence for elongating growth. Pliable plastic cuffs impregnated with colchicine or vehicle control were placed around sciatic nerves of anesthetized rats. Assays were performed after $48 \mathrm{hr}$. $A$, Electron microscopy confirmed that axons in the nerve segment surrounded by the plastic cuff remained intact. Colchicine produces an increase in irregular profiles of myelinated axons compared to within a single population of cells. It is clear, however, that interruption of centrally projecting axons does produce a general shift in the growth capabilities of DRG neurons but fails to elicit the same competence for elongating growth induced by peripheral lesions.

\section{DISCUSSION}

Our findings indicate that most, if not all, adult sensory neurons are constitutively competent to support arborizing axon growth, characterized by a high frequency of branching and a concomitantly limited linear extension of individual processes. We find, however, that these cells are unable to initiate or sustain rapid, linear extension of axons-a mode of growth characteristic of regenerating axons in vivo-unless they undergo a transcriptiondependent transition triggered in most neurons by the interruption of retrogradely transported signals derived from or activated by interaction with peripheral targets. These findings provide evidence that axonal sprouting in the adult nervous system can be mediated by a molecular apparatus distinct from that involved in nerve regeneration. The complement of proteins continually delivered to mature axons and their terminals is sufficient to support some forms of growth that could underlie structural remodeling in adult nervous systems. Indeed, recent studies have shown that some of the proteins involved in vesicle trafficking and transmitter release at synaptic terminals participate in neurite extension (Feany and Buckley, 1993; Osen-Sand et al., 1993; Ferreira et al., 1994), suggesting that there may be extensive overlap in the molecular apparatus supporting cytoskeletal plasticity and membrane trafficking during synaptic transmission and during some forms of axon sprouting.

Although clearly distinct from elongating processes, the arborizing neurites extended by naive DRG neurons actually encompass a broad range of individual morphologies (see Fig. $3 A$ ), and subpopulations of DRG neurons differ in their propensity to extend arborizing processes under various conditions. DRG cells are a heterogeneous population of neurons that innervate distinct targets and, in the absence of injury, express different neurotrophin receptors, synaptic components, and growth-associated proteins (Schreyer and Skene, 1991; Wong and Oblinger, 1991; Weise et al., 1992; Zhang et al., 1995; Snider and Wright, 1996). Thus, although genes expressed in adult DRG neurons are sufficient for axonal arborization, differential expression of additional growthrelated genes may account for significant variation among subpopulations of DRG neurons in the type and extent of arborizing growth they can support and in the types of neurotrophins or

vehicle controls, consistent with its disruption of microtubules. In contrast, sciatic nerve crush produces dramatic degeneration of axons just proximal to the crush site. $B$, The percentage of elongating (black bars) and arborizing cells ( gray bars) after $16 \mathrm{hr}$ in culture. Colchicine did not block the induction of elongating growth after peripheral axotomy (Ax./Colch.), but in the absence of sciatic nerve crush, the drug induced competence for elongating growth in otherwise uninjured neurons (Colch.). Data from naive $(N$.$) and pre-axotomized (A x$.$) untreated animals are provided for$ comparison. Application of cuffs containing vehicle alone (Veh.) had no effect on the onset of axon elongation (compare to $16 \mathrm{hr}$ time points in Fig. $5 A, B)$. Each bar represents the mean $\pm \mathrm{SD}$ of four separate experiments with duplicate cultures in each experiment. $C$, Quantitative analysis of neurite branching and length shows that neurites extended in three separate experiments by neurons from colchicine-treated animals ( filled squares) resemble the elongating axons of pre-axotomized neurons and are clearly segregated from the arborizing neurites extended after application of vehicle-containing cuff (open circles). 

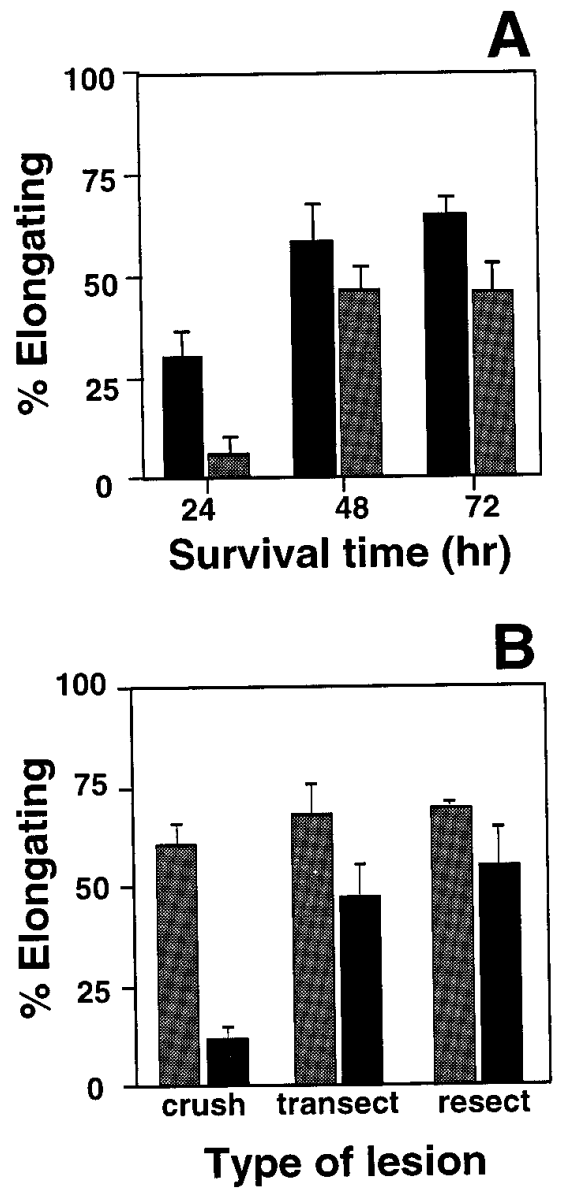

Figure 9. Competence for elongating growth is regulated by a retrograde signaling pathway(s) activated by contact with peripheral targets. $A$, The length of the proximal nerve stump affects the timing, but not the extent, of the transition to elongating growth competence. Sciatic nerve crush was performed either $1.0-1.5 \mathrm{~cm}$ (black bars) or $5.0-5.5 \mathrm{~cm}$ (gray bars) from neuronal cell bodies, and neurons were removed and transferred to tissue culture 24,48 , or $72 \mathrm{hr}$ later. By $48 \mathrm{hr}$ after injury, both proximal and distal lesions produced a large increase in the number of neurons able to extend elongating axons by $16 \mathrm{hr}$ after plating (fewer neurons are injured by the distal lesion, so the maximal response is lower than after proximal injury). The response to proximal crush reaches $45 \%$ of the maximum response by $24 \mathrm{hr}$ after injury. In contrast, the response to a more distal lesion by $24 \mathrm{hr}$ is only $12 \%$ of the maximum. This may reflect time required for the depletion of retrogradely transported inhibitory molecules in longer proximal nerve segments. Each bar represents the mean \pm SD of three separate experiments with duplicate cultures in each experiment. $B$, Sciatic nerves were subjected to a crush lesion, which permits effective regeneration of axons, or complete transection or resection of a $0.5 \mathrm{~cm}$ nerve segment, both of which delay or prevent reinnervation of peripheral targets. DRG neurons were removed 1 week (shaded bars) or 8 weeks (black bars) after injury, and plated for $16 \mathrm{hr}$ in vitro. By 1 week after injury, all three types of lesion had stimulated competence for elongating growth. By 8 weeks after injury, competence for elongation had declined in neurons with crush lesion but remained elevated after nerve transection or resection. Each bar represents the mean $\pm \mathrm{SD}$ of three separate experiments with duplicate cultures in each experiment.

other environmental cues that can elicit arborization in the absence of new gene expression.

In contrast to arborizing growth, the genes constitutively expressed in naive adult neurons are not adequate for these cells to initiate or sustain the more rapid, elongating mode of axon extension. Successful nerve regeneration requires the rapid, linear extension of individual axonal processes for distances on the order
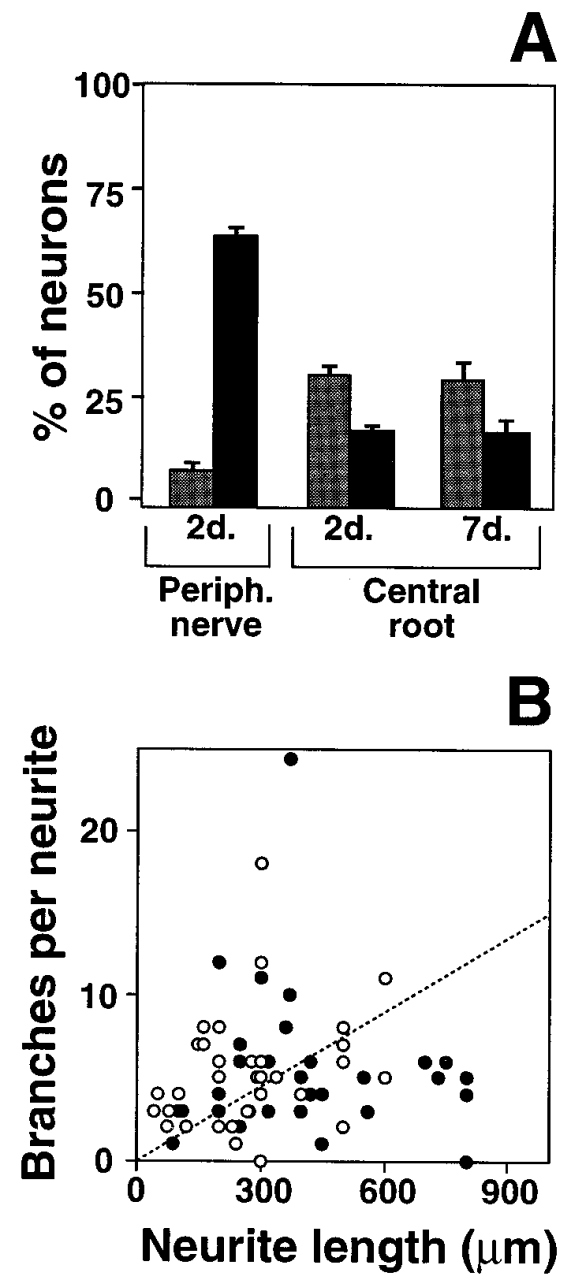

Figure 10. Central and peripheral axotomy affect the growth characteristics of DRG neurons differently. DRG neurons subjected to central axotomy displayed growth characteristics intermediate between naive and peripherally axotomized neurons. $A$, Fewer neurons were able to elongate (black bars) 2 or $7 \mathrm{~d}$ after a central root crush than $2 \mathrm{~d}$ after a peripheral crush. In addition, more neurons extended arborizing neurites (gray bars) after the central root lesions. Each bar represents the mean \pm SD of three separate experiments with duplicate cultures in each experiment. $B$, Analysis of neurite length and branching revealed that the neurites in these cultures did not fall into distinct groups but, instead, covered a wide range of intermediate morphologies. Filled circles, Neurites measured in $16 \mathrm{hr}$ cultures from ganglia removed $2 \mathrm{~d}$ after dorsal root crushes were performed in vivo. Open circles, Neurites measured in $16 \mathrm{hr}$ cultures from ganglia removed $7 \mathrm{~d}$ after dorsal root crushes were performed.

of millimeters to centimeters (McQuarrie et al., 1978; Forman et al., 1980; McQuarrie and Grafstein, 1981). In its rate of advance and low frequency of branching, the elongating mode of growth we describe in culture closely resembles the regeneration of axons in injured nerves. In our cultures, the transition to elongating growth requires new or ongoing transcription after the interruption of mature axons, but only for a limited period after injury. Once cells have completed this transition, they are able to carry out robust axon elongation in the continuous presence of DRB for periods up to $16 \mathrm{hr}$ (Figs. 2, 7). Several observations argue that the effects of DRB result from a selective inhibition of gene expression instead of a global suppression of $\mathrm{mRNA}$ or protein production. Early exposure of naive DRG neurons to DRB, followed by $12 \mathrm{hr}$ of recovery, profoundly inhibits the onset of elongating 
growth but does not grossly alter protein synthesis, which reflects both the abundance and the active translation of mRNA in the cells. Because transient exposure to DRB does not result in a gross alteration in translated mRNAs in the naive DRG neurons, the inability of these cells to support elongation must result from a more selective deficit in specific mRNA species. Furthermore, global suppression of mRNA synthesis by DRB is not sufficient to suppress competence for elongation in neurons pre-axotomized in vivo or allowed at least $12 \mathrm{hr}$ to respond in vitro to axotomy associated with dissociation and plating. Thus, the transcriptiondependent event(s) required for the onset of elongation appear to involve selective changes in mRNA abundance, rather than a global increase in mRNA or protein production after axotomy.

The most parsimonious interpretation of these findings is that DRB blocks the onset of elongating growth by preventing a selective, axotomy-induced increase in expression of one or more genes above the levels characteristic of uninjured adult neurons in vivo. Although DRB inhibition of RNA polymerase II produces a nonselective blockade of all mRNA synthesis, the earliest and most pronounced effect of this inhibition will be to prevent any increase in mRNA species induced in response to axotomy. For genes expressed at relatively high levels in adult neurons before explantation, preexisting pools of mRNA should permit continued production of protein for several hours during transient disruption of transcription. This would explain why DRB no longer interferes with the onset of elongating growth once neurons have been permitted 12-24 hr to transcribe new mRNAs after axotomy. This period of active transcription would allow the cells to establish a critical pool of mRNA species required for the transition to elongating growth.

Extensive biochemical analysis has shown that interruption of peripheral axons does in fact induce selective accumulation of several specific mRNA species, including those coding for prominent components of axonal growth cones (Basi et al., 1987; Hoffman and Cleveland, 1988; Hoffman, 1989; Miller et al., 1989; Verge et al., 1990; Weise et al., 1992; Mearow et al., 1994). No one of these proteins, however, has been shown to be essential for axon elongation. For example, elimination of GAP-43, a protein frequently correlated with developmental and regenerative axon growth, does not abolish axon extension, although it dramatically alters adhesive properties and the responses of growth cones to guidance and inhibitory cues (Aigner and Caroni, 1995; Strittmater et al., 1995). Similarly, a deficiency in c-src interferes with axon extension only on specific substrata (Ignelzi et al., 1994). Our data, however, support the view that some combination of the genes that exhibit enhanced expression in response to peripheral axotomy is essential for elongation.

One alternative possibility is that a critical molecule(s) involved in triggering the cell body transition to elongation is encoded by a constitutively expressed, but very rapidly degraded, mRNA. If both the mRNA and the protein it encodes were very rapidly degraded, ongoing transcription would be required to maintain effective levels of the relevant triggering component(s) for a defined period after axotomy. For such a model, the critical mRNA would need to carry out an irreversible or selfperpetuating step in triggering competence for elongating growth, rather than having a continuing role in maintaining the cell's competence for elongation, because interruption of transcription beginning 12-24 hr after axotomy no longer prevents the onset of elongating growth. Similarly, neurons axotomized in vivo 2-7 d before explantation are able to initiate and sustain elongating growth in the continuous presence of the transcription inhibitor for up to $16 \mathrm{hr}$ (Fig. 1). With either model, our results indicate that regenerative growth depends on a molecular apparatus distinct from that underlying common forms of growth and remodeling in the normal adult nervous system.

Numerous studies have shown previously that various types of neurite outgrowth can be supported by embryonic neurons, as well as by neuronal tumor cell lines, in vitro (Gunning et al., 1981; Dotti et al., 1988; Smalheiser, 1989). Furthermore, it is clear that different modes of growth are supported at progressive stages of neuronal differentiation (Dotti et al., 1988; Jhaveri et al., 1991) and that progression from one stage to another can involve changes in the proteins routed into growing neurites (Goslin et al., 1990). Our observations that two distinct modes of growth can be supported by fully differentiated, mature DRG neurons support the conclusions of Diamond et al. (1987), which were based on conditions that elicit terminal sprouting or regenerative growth from these same neurons in vivo. They reported that sprouting from uninjured axon terminals in skin, but not successful regeneration of long axons, was sensitive to loss of NGF. This supports the view that the arborizing and elongating modes of growth described here may correspond to axon sprouting and regeneration, respectively. Our present observations show further that the elongating mode of growth is ordinarily suppressed by signaling pathways activated through interactions of axons with peripheral targets.

In the mammalian CNS, axon injury often fails to induce the changes in gene expression typically elicited by peripheral axotomy (Skene, 1989; Doster et al., 1991; Schaden et al., 1994; Tetzlaff et al., 1994). Our findings support the hypothesis that failure to induce an appropriate transcriptional response can restrict the ability of many CNS neurons to support axon regeneration. Classically, the local sprouting of CNS axons at a site of injury has been taken to indicate that CNS neurons successfully initiate axon regeneration but are then impeded by the nonpermissive environment of CNS white matter (Cajal, 1928). Our results indicate that local sprouting of axons is not a sign that neurons have become competent to sustain longer-distance elongation of axons. In some cases, the ability of CNS neurons to support regrowth of long axons has been demonstrated by replacing or neutralizing inhibitory influences in the CNS white matter environment (David and Aguayo, 1981; So and Aguayo, 1985; Schnell et al., 1990). Recently, it has become apparent that the regenerating axons arise from a fraction of injured neurons, principally under conditions that also elicit cell body responses typical of peripheral nerve injury (Richardson and Issa, 1984; Campbell et al., 1991; Doster et al., 1991; Schaden et al., 1994). Of particular relevance here, Richardson and Issa (1984) showed that ascending sensory axons in the spinal cord, which arise from the centrally projecting branches of DRG neurons, are unable to regenerate when transected in the spinal cord and presented with a segment of peripheral nerve as a supportive growth environment. Interruption of the peripheral axons by sciatic nerve injury, however, stimulated DRG neurons to undergo effective regeneration of their spinal axons through the peripheral nerve grafts. Analyses of CNS axon regeneration in vivo thus support the conclusion that a conversion from competence for arborization to competence for elongation represents a fundamental limiting event for effective regeneration of long projecting axons.

The effect of dorsal root lesions on the growth properties of DRG neurons indicates that the transition from arborizing to elongating growth does not always occur in a single, coordinated step and that intermediate states can be maintained in vivo. 
One explanation for such intermediate states is the induction, or persistent expression, of a subset of genes required for elongating growth. The transcription factor c-jun, for example, is induced in a small and variable number of DRG neurons after dorsal rhizotomy (Jenkins, 1993). Expression of major cytoskeletal proteins occurs but is attenuated compared to peripheral lesions (Wong and Oblinger, 1990). Expression of GAP-43, which is strongly induced after sciatic nerve injury, is not affected by dorsal root injury (Schreyer and Skene, 1993; Chong et al., 1994). The range of growth characteristics observed after dorsal root injury may also result from a preexisting heterogeneity in expression of growth-associated proteins that complement those activated by the dorsal root lesion. For example, subsets of adult neurons, including DRG neurons, continue to express GAP-43 and other proteins associated with developmental axon growth (Skene and Willard, 1981a; Weise et al., 1992; Schreyer and Skene, 1993). Either model is consistent with the view that the elongating mode of growth that emerges after peripheral axotomy does not result from expression of a single growth-associated gene but, rather, from some combination of the genes induced by the peripheral lesion. The results of the dorsal root lesion experiments show further that the critical genes involved in the transition to elongating growth do not have to be controlled coordinately. Our findings, therefore, support a model in which a majority of neurons in the intact adult remain competent for some forms of axonal arborization over a limited spatial range. Constitutive or induced expression of individual genes required for the regeneration of axons can modify the growth properties of individual cells without activating full competence for elongating growth.

Characterization of the transition between distinct growth modes in vitro now provides an experimentally accessible framework for investigating how individual genes, known or previously unidentified, alter specific features of axonal growth and for determining which combinations of these proteins are required for effective axon elongation.

\section{REFERENCES}

Aigner L, Caroni P (1995) Absence of persistent spreading, branching and adhesion in GAP-43-depleted growth cones. J Cell Biol 128:647-660.

Aigner L, Arber S, Kapfhammer JP, Laux T, Schneider C, Botteri F, Brenner H-R, Caroni P (1995) Overexpression of the neural growthassociated protein Gap-43 induces nerve sprouting in the adult nervous system of transgenic mice. Cell 83:269-278.

Antonini A, Stryker MP (1993) Development of individual geniculocortical arbors in cat striate cortex and effects of binocular impulse blockade. J Neurosci 13:3549-3573.

Argiro V, Johnson MI (1982) Patterns and kinetics of neurite extension from sympathetic neurons in culture are age dependent. J Neurosci 2:503-512.

Bailey CH, Montarolo P, Chen M, Kandel ER, Schacher S (1992) Inhibitors of protein and RNA synthesis block structural changes that accompany long-term heterosynaptic plasticity in Aplysia. Neuron 9:749-758.

Basi GS, Jacobson RD, Virag I, Schilling J, Skene JHP (1987) Primary structure and transcriptional regulation of GAP-43, a protein associated with nerve growth. Cell 49:785-791.

Bendotti C, Servadio A, Samanin R (1991) Distribution of GAP-43 mRNA in the brain stem of adult rats as evidenced by in situ hybridization: localization within monoaminergic neurons. J Neurosci 11:600-607.

Bendotti C, Pende M, Samanin R (1994) Expression of GAP-43 in the granule cells of rat hippocampus after seizure-induced sprouting of mossy fibres: in situ hybridization and immunocytochemical studies. Eur J Neurosci 6:509-515.

Benowitz LI, Routtenberg A (1987) A membrane phosphoprotein associated with neural development, axonal regeneration, phospholipid metabolism, and synaptic plasticity. Trends Neurosci 10:521-531.
Bottenstein JE, Sato GH (1979) Growth of a rat neuroblastoma cell line in serum free supplemented medium. Proc Natl Acad Sci USA 76:514-517.

Cajal S (1928) Degeneration and regeneration of the nervous system. London: Oxford UP.

Campbell G, Anderson PN, Turmaine M, Lieberman AR (1991) GAP-43 in the axons of mammalian CNS neurons regenerating into peripheral nerve grafts. Exp Brain Res 87:67-74.

Caroni P, Becker M (1992) The downregulation of growth-associated proteins in motoneurons at the onset of synapse elimination is controlled by muscle activity and IGF1. J Neurosci 12:3849-3861.

Cavazos JE, Golarai G, Sutula TP (1991) Mossy fiber synaptic reorganization induced by kindling: time course of development, progression, and permanence. J Neurosci 11:2795.

Chong MS, Reynolds ML, Irwin N, Coggeshall RE, Emson PC, Benowitz LI, Woolf CJ (1994) Gap-43 expression in primary sensory neurons following central axotomy. J Neurosci 14:4375-4384.

Chu DTW, Klymkowsky MW (1989) The appearance of acetylated $\alpha$-tubulin during early development and cellular differentiation in $\mathrm{Xe}$ nopus. Dev Biol 136:104-117.

Collins F, Lee MR (1982) A reversible developmental change in the ability of ciliary ganglion neurons to extend neurites in culture. J Neurosci 2:424-430.

David S, Aguayo AM (1981) Axonal elongation into peripheral nervous system "bridges" after central nervous system injury in rats. Science 214:931-933.

Darian-Smith C, Gilbert CD (1994) Axonal sprouting accompanies functional reorganization in adult cat striate cortex. Nature 368:737-740.

de la Monte SM, Federoff HJ, Ng SC, Grabczyk E, Fishman MC (1989) Gap-43 gene expression during development: persistence in a distinctive set of neurons in the mature central nervous system. Dev Brain Res 46:161-168.

Delree P, Ribbens C, Martin D, Rogister B, Lefebvre PP, Rigo JM, Leprince P, Schoenen J, Mooned G (1993) Plasticity of developing and adult dorsal root ganglion neurons as revealed in vitro. Brain Res Bull 30:231-237.

Diamond J, Coughlin M, MacIntyre L, Holmes M, Visheau B (1987) Evidence that endogenous beta-nerve growth factor is responsible for the collateral sprouting, but not the regeneration of nociceptive axons in adult rats. Proc Natl Acad Sci USA 84:6596-6600.

Dotti CG, Sullivan CA, Banker GA (1988) The establishment of polarity by hippocampal neurons in culture. J Neurosci 8:1454-1468.

Doster SK, Lozano AM, Aguayo AJ, Willard MB (1991) Expression of the growth-associated protein GAP-43 in adult rat retinal ganglion cells following axon injury. Neuron 6:1-13.

Feany MB, Buckley K (1993) The synaptic vesicle protein, synaptotagmin, promotes the formation of filopodia in fibroblasts. Nature 364:537-540.

Ferriera A, Kosic KS, Greengard P, Han HQ (1994) Aberrant neurites and synaptic vesicle protein deficiency in synapsin II-depleted neurons. Science 264:977-979.

Florence SL, Kaas JH (1995) Large-scale reorganization at multiple levels of the somatosensory pathway follows therapeutic amputation of the hand in monkeys. J Neurosci 15:8083-8095.

Forman DS, McQuarrie IG, Labore FW, Wood DK, Stone LS, Braddock CH, Fuchs DA (1980) Time course of the conditioning lesion effect on axonal regeneration. Brain Res 182:180-185.

Greenough WT, Bailey CH (1988) The anatomy of a memory: convergence of results across a diversity of tests. Trends Neurosci 11:142-147.

Goslin K, Schreyer DJ, Skene JHP, Banker G (1990) Changes in the distribution of GAP-43 during development of neuronal polarity. J Neurosci 10:588-602.

Gunning PW, Landreth GE, Bothwell MA, Shooter ES (1981) Differential and synergistic actions of nerve growth factor and cyclic AMP in PC12 cells. J Cell Biol 89:240-245.

Hall ZW, Sanes JR (1993) Synaptic structure and development: the neuromuscular junction. Cell 72:99-121.

Hess DT, Patterson SI, Smith DS, Skene JHP (1993) Neuronal growth cone collapse and inhibition of protein fatty acylation by nitric oxide. Nature 366:562-565.

Himes BT, Tessler A (1989) Death of some dorsal root ganglion neurons and plasticity of others following sciatic nerve section in adult and neonatal rats. J Comp Neurol 284:215-230.

Hoffman PN (1989) Expression of GAP-43, a rapidly transported growth-associated protein, and class II beta tubulin, a slowly transported cytoskeletal protein, are coordinated in regenerating neurons. J Neurosci 9:893-897. 
Hoffman PN, Cleveland DW (1988) Neurofilament and tubulin expression recapitulates the developmental pattern during axonal regeneration: induction of a specific $\beta$-tubulin isotype. Proc Natl Acad Sci USA 84:4530-4533.

Ignelzi MA, Miller DR, Soriano P, Maness PF (1994) Impaired neurite outgrowth of src-minus cerebellar neurons on the adhesion molecule L1. Neuron 12:873-874.

Isaacson LG, Saffran BN, Krutcher KA (1992) Nerve growth factorinduced sprouting of mature uninjured sympathetic axons. J Comp Neurol 326:327.

Jenkins R, Tetzlaff W, Hunt SP (1993) Differential expression of immediate early genes in rubrospinal neurons following axotomy in the rat Eur J Neurosci 5:203-209.

Kimura H, Fisher WH, Schubert D (1990) Structure, expression and function of a schwannoma-derived growth factor. Nature 348:257-260.

Landreth GE, Agranoff BW (1976) Explant culture of adult goldfish retina: effect of prior optic nerve crush. Brain Res 118:299-303.

Lindell T, Weinberg F, Morris PW, Roeder RG, Rutter WJ (1970) Specific inhibition of Nuclear RNA polymerase II by $\alpha$-amanitin. Science 170:447-449.

Lindsay R (1988) Nerve growth factors (NGF, BDNF) enhance axonal regeneration but are not required for survival of adult sensory neurons. J Neurosci 8:2394-2405.

Maness PF, Aubry M, Shores CG, Frame L, Pfenninger KH (1988) c-src gene product in developing rat brain is enriched in nerve growth cone membranes. Proc Natl Acad Sci USA 85:5001-5005.

Matsuoka I, Meyer M, Thoenen H (1991) Cell-type-specific regulation of nerve growth factor (NGF) synthesis in non-neuronal cells: comparison of Schwann cells with other cell types. J Neurosci 11:3165-3177.

McQuarrie IG, Grafstein B (1981) Effect of a conditioning lesion on optic nerve regeneration in goldfish. Brain Res 216:253-264.

McQuarrie IG, Grafstein B, Dreyfus CF, Gershon MD (1978) Regeneration of adrenergic axons in rat sciatic nerve: effect of a conditioning lesion. Brain Res 141:21-34.

Mearow KM, Kril Y, Gloster A, Diamond J (1994) Expression of NGF receptor and GAP-43 mRNA in DRG neurons during collateral sprouting and regeneration of dorsal cutaneous nerves. J Neurobiol 25:127-142.

Miller FD, Tetzlaff W, Bisby MA, Fawcett JW, Milner RJ (1989) Rapid induction of the major embryonic $\alpha$-tubulin mRNA in adults following neuronal injury. J Neurosci 9:1452-1463.

Moskowitz PF, Smith R, Pickett J, Frankfurter A, Oblinger MM (1993) Expression of the class III beta-tubulin gene during axonal regeneration of rat dorsal root ganglion neurons. J Neurosci Res 34:129-134.

O'Leary DM, Ruff NL, Dyck RH (1995) Development, critical period plasticity, and adult reorganizations of mammalian somatosensory systems. Curr Opin Neurobiol 4:535-544.

Osen-Sand A, Catsicas M, Staple JK, Jones KA, Ayala G, Knowles J, Grenningloh G, Catsicas S (1993) Inhibition of axonal growth by SNAP-25 antisense oligonucleotides in vitro and in vivo. Nature 363:445-448.

Pfeiffer SE, Wechsler W (1972) Biochemically differentiated neoplastic clone of Schwann cells. Proc Natl Acad Sci USA 69:2885-2889.

Purves D (1988) A trophic theory of neural connections. Cambridge, MA: Harvard UP.

Purves D, Voyvodic JT, Magrassi L, Yawo H (1987) Nerve terminal remodelling visualized in living mice by repeated examination of the same neuron. Science 238:1122-1126.

Represa A, Pollard H, Moreau J, Ghilini G, Khrestchatisky M, Ben-Ari Y (1993) Mossy fiber sprouting in epileptic rats is associated with a transient increased expression of $\alpha$-tubulin. Neurosci Lett 156:149-152.

Richardson PM (1994) Ciliary neurotrophic factor: a review. J Pharmacol Exp Ther 63:187-198.

Richardson PM, Issa VMK (1984) Peripheral injury enhances regeneration of spinal axons. Nature 284:264-265.

Schaden H, Steurmer CAO, Bahr M (1994) GAP-43 immunoreactivity and axon regeneration in retinal ganglion cells of the rat. $\mathbf{J}$ Neurobiol 25:1570-1578.

Schnell L, Schwab ME (1990) Axonal regeneration in the rat spinal cord produced by an antibody against myelin-associated neurite inhibitors. Nature 343:269-272.

Schreyer D, Skene JHP (1991) Fate of Gap-43 in ascending spinal axons of DRG neurons after peripheral nerve injury: delayed accumulation and correlation with regenerative potential. J Neurosci 11:3738-3751.

Skene JHP (1989) Axonal growth-associated proteins. Annu Rev Neurosci 12:127-156.

Skene JHP (1991) Retrograde pathways controlling expression of a major growth cone component in the adult CNS. In: The nerve growth cone (Letourneau PC, Kater SB, Macagno ER, eds), pp 463-475. New York: Raven.

Skene JHP, Willard M (1981a) Axonally transported proteins associated with axon growth in rabbit central and peripheral nervous systems. J Cell Biol 89:96-103.

Skene JHP, Willard M (1981b) Changes in axonally transported proteins during axon regeneration in toad retinal ganglion cells. J Cell Biol 89:86-95.

Smalheiser NR (1989) Analysis of slow-onset neurite formation in NG108-15 cells: implications for a unified model of neurite elongation. Dev Brain Res 45:49-57.

Snider WD, Wright DE (1996) Neurotrophins cause a new sensation. Neuron 16:229-232.

So K-F, Aguayo AJ (1985) Lengthy regrowth of cut axons from ganglion cells after peripheral nerve transplantation in to the retinal of adult rats. Brain Res 328:349-354.

Strittmatter SM, Valenzuela D, Kennedy TE, Neer EJ, Fishman MC (1990) $G_{o}$ is a major growth cone protein subject to regulation by GAP-43. Nature 344:836-841.

Strittmatter SM, Frankhauser C, Huang PL, Mashimo H, Fishman MC (1995) Neuronal pathfinding is abnormal in mice lacking the neuronal growth cone protein GAP-43. Cell 80:445-453.

Tamm I, Sehgal PB (1978) Halobenzimidazole ribosides and RNA synthesis of cells and viruses. J Adv Virol Res 22:187-258.

Tetzlaff W, Kobayashi NR, Giehl KM, Tsui BJ, Cassar SL, Bedard AM (1994) Response of rubrospinal and corticospinal neurons to injury and neurotrophins. Prog Brain Res 103:271-286.

Touck PL, Nadler JV (1985) Evidence of functional mossy fiber sprouting in hippocampal formation of kainic acid-treated rats. J Neurosci 5:1016-1022.

Verge VMK, Tetzlaff W, Richardson PM (1990) Correlation between GAP-43 and nerve growth factor receptors in rat sensory neurons. J Neurosci 10:926-934.

Verge VMK, Xu Z, Xu X-J, Weisenfeld-Hallin Z, Høkfelt T (1992) Marked increase in rat nitric oxide synthase mRNA in rat dorsal root ganglia after peripheral axotomy: in situ hybridization and functional studies. Proc Natl Acad Sci USA 89:11617-11621.

Walters ET, Alizadeh H, Castro GA (1991) Similar neuronal alterations induced by axonal injury and learning in Aplysia. Science 253:797-799.

Wanaka A, Carroll SL, Milbrandt J (1993) Developmentally regulated expression of pleiotrophin, as novel heparin binding growth factor in the nervous system of the rat. Brain Res Dev Brain Res 72:133-144.

Weise UH, Ruth JL, Emson PC (1992) Differential expression of growthassociated protein (GAP-43) mRNA in rat primary sensory neurons after peripheral nerve lesion: a non-radioactive in situ hybridization study. Brain Res 592:141-156.

Wong J, Oblinger MM (1990) A comparison of peripheral and central axotomy effects on neurofilament and tubulin gene expression in rat dorsal root ganglion neurons. J Neurosci 10:2215-2222.

Wong J, Oblinger MM (1991) NGF rescues substance P expression but not neurofilament or tubulin gene expression in axotomized sensory neurons. J Neurosci 11:543-552.

Wooley CS, McEwen BS (1992) Estradiol mediates fluctuations in hippocampal synapse density during the estrous cycle in the adult rat. J Neurosci 12:2549-2554.

Zhang X, Xu ZQ, Bao L, Dagerlind A, Hokfelt T (1995) Complementary distribution of receptors for neurotensin and NPY in small neurons of rat lumbar DRGs and regulation of the receptors and peptides after peripheral axotomy. J Neurosci 15:2733-2747. 